\title{
O ensino de expressões idiomáticas à luz da lexicografia pedagógica
}

\author{
Gislaine Rodrigues Matias \\ UNESP (PPG-EL) \\ Maria Cristina Parreira \\ UNESP
}

\begin{abstract}
Resumo
No contexto atual dos estudos lexicográficos, cada vez mais vêm sendo discutidas questões que tratam da relação entre os conhecimentos teóricos sobre o léxico e as práticas pedagógicas envolvidas no seu ensino. Porém, nesse contexto, ainda é dada pouca atenção ao léxico especial da Língua Portuguesa, como os neologismos, os estrangeirismos, as gírias e as expressões idiomáticas. Há muitos estudos teóricos sobre cada um desses fenômenos, mas são raros os estudos que visam a uma organização e inclusão dessas unidades especiais no ensino da Língua Portuguesa. Por conta disso, este artigo tem o objetivo de apresentar uma reflexão sobre o ensino de expressões idiomáticas e aplicação de dicionários especiais para o ensino de Língua Portuguesa no nível fundamental, embora muitos acreditem que é apenas para o ensino de línguas estrangeiras que esses dicionários são necessários.
\end{abstract}

Palavras-chave: dicionários especiais; expressões idiomáticas; lexicografia pedagógica

\begin{abstract}
In the current context of lexicographical studies, there have been increasing discussions concerning the issue of the relationship between theoretical knowledge of the lexicon and pedagogical practices involved in its teaching. However, in this context, the special lexicon of Portuguese such as neologisms, foreign words, slang and idioms has received little attention from researchers. There are many theoretical studies on each one of these phenomena, but few studies aim at an organization and inclusion of special units in the teaching of Portuguese. For this reason, this article presents a reflection on the teaching of idioms, and, despite the widely held belief that dictionaries are only needed for the teaching of foreign languages, the article suggests the implementation of special dictionaries for the teaching of Portuguese Language in elementary education.
\end{abstract}

Keywords: special dictionaries; idiomatic expressions; pedagogical lexicography 


\section{INTRODUÇÃO}

A Lexicografia pedagógica, de acordo com Welker (2008:13), pode ser distinta em duas atividades: lexicografia prática e lexicografia teórica. A primeira volta-se à elaboração de dicionários, já a segunda, também conhecida por metalexicografia, voltase a todas as considerações acerca dos dicionários, focalizando, especialmente, os resultados adquiridos com o conhecimento alcançado e divulgado pelo estudo dos dicionários pedagógicos.

Dentre as várias preocupações com o ensino, há aquelas que já vêm sendo alvo de estudos pelos linguistas, como o ensino da gramática e do léxico, mas há outras que ainda não são muito estudadas e são pouco conhecidas pelos professores em exercício. É o caso do ensino de expressões idiomáticas da língua portuguesa no ensino fundamental. Acredita-se que, por fazerem parte da linguagem coloquial, sendo mais recorrentes na fala que na escrita, não precisariam fazer parte dos currículos escolares. No entanto, elas constituem uma parcela do léxico nem sempre dominada pelos seus falantes, justamente por sua característica principal, isto é, por serem formadas de unidades cuja soma de sentidos não corresponde ao resultado semântico final. Quando falamos pagar o pato, por exemplo, não basta saber o significado de pagar e de pato, mas sim entender que se trata do fato "sofrer as consequências dos atos de outra pessoa" (Riva, 2008).

Pretendemos, neste artigo, dentro de um panorama teórico e prático, à luz dos preceitos da Lexicografia Pedagógica propostos por Welker (2004, 2006 e 2008), contribuir para um ensino mais dinâmico, neste caso, tratando de uma parcela especial do léxico - as expressões idiomáticas - e incentivando o uso de dicionários que tratam dessas unidades nas aulas de Língua Portuguesa.

\section{O CONCEITO DE EXPRESSÃO IDIOMÁTICA}

As expressões idiomáticas (EIs) incluem-se no léxico especial das línguas. Xatara (1998) conceitua EI da seguinte maneira: “expressão idiomática é uma lexia complexa indecomponível, conotativa e cristalizada em um idioma pela tradição cultural". Essa definição nos faz notar que as EIs são unidades ricas da língua, totalmente procedentes do cotidiano das pessoas, sendo consagradas pelo uso. São bastante frequentes e seu uso pode variar muito de geração para geração, pois para usar 
uma expressão é necessário compreender seu significado, que não é evidente se esse conhecimento não for partilhado entre os falantes. Remetemos à fala de Ortíz Alvarez (2000) para corroborar essa afirmação:

[...] as expressões idiomáticas refletem o lado dinâmico da língua, a sua adaptação constante às necessidades comunicacionais do momento, tanto que podem desaparecer logo depois de seu surgimento, se bem que muitas ficam e se incorporam ao inventário lexical da língua. (Ortíz Alvarez, 2000:73)

As ideias de Xatara e Ortíz Alvarez se complementam, uma vez que ambas consideram as expressões idiomáticas como construto linguístico cultural, rico e dinâmico. Também acreditamos que as expressões refletem a dinamicidade da língua e evocamos aqui Biderman (2001), quando diz que os idiomatismos são consagrados pelo uso e que seus significados conotativos podem, muitas vezes, direcioná-lo. Nesse sentido, acrescentamos ainda a ideia, segundo Tagnin (1989), de que para um estudante compreender como esse léxico especial se constitui na língua é necessário que não se prenda somente às regras e ao léxico.

Podemos afirmar, então, que assim como é preciso aprender o significado das EIs para usá-las no cotidiano, também é preciso ensiná-las nas escolas para aumentar a riqueza vocabular dos alunos. É possível que alguns queiram contestar essa necessidade, visto que a transmissão desses conhecimentos conotativos geralmente se dá naturalmente na linguagem falada. Contudo, a sistematização do ensino desse fenômeno pode trazer contribuição também para a melhor adequação nas redações escolares, inclusive no domínio da linguagem culta, por meio de exercícios que auxiliem na decodificação dos significados das expressões diferenciando os níveis de uso. Cabe ressaltar que as pesquisas existentes sobre o assunto normalmente tratam da equivalência dessas expressões em línguas estrangeiras e não em seu tratamento no âmbito da língua materna.

As EIs exercem várias funções, uma delas é a de simplificar uma argumentação, permitindo ironizar ou sugerir algo que não se ousa falar diretamente. Desse modo, elas exigem uma interpretação, sendo assim, seu domínio possibilita que se conheça ainda mais o idioma. Dentro do conteúdo "figuras de linguagem", sempre presente nos currículos escolares, pode-se melhor trabalhar a compreensão das EIs, pois, como nos fala Ortíz Alvarez (2000:124), “a extensão de sentido dessas unidades é metafórica”. 
Quando um linguista ou gramático trata da conotação, refere-se ao sentido figurado que uma palavra ou expressão adquire, dependendo do contexto em que está inserida. As EIs são ótimos exemplos de conotação, pois, em grande parte delas, pretende-se expressar um sentido diferente daquele que pode ser compreendido ao "pé da letra" por cada unidade que as compõem.

Para melhor desenvolver essa questão, pode-se recorrer novamente ao trabalho realizado por Xatara (1998:3), no qual a autora afirma que a interpretação conotativa de EIs revela figuras de estilo de linguagem como metonímias, comparações e metáforas. Um exemplo acerca dessa interpretação pode ser a EI engolir sapo, que conotativamente significa "tolerar situações desagradáveis sem reclamar” (Riva, 2008), e não, engolir literalmente o anfíbio.

Como já argumentamos, para que essa interpretação seja desenvolvida corretamente pelo aprendiz, este necessitará conhecer melhor seu idioma e as características das EIs usadas. O ensino dessas unidades torna-o capaz de analisá-las e de passar, assim, a perceber mais claramente como elas são compostas e cristalizadas na língua, finalmente auxiliando-o em sua construção linguística e intelectual.

Quanto à estrutura, as EIs são constituídas pela combinatória de palavras. Elas só estabelecerão um sentido metafórico se seus elementos forem agrupados, embora isso não signifique que os componentes de uma EI não possam ser providos do sentido conotativo, mas o valor da EI completa é diferente daquele das unidades isoladas. A construção enfiar o pé na jaca, por exemplo, pode se relacionar à ideia de alguém ter pisado na fruta, já que é possível uma interpretação literal, mas enquanto EI, apresenta sentido conotativo, entendo-se, geralmente por meio do contexto, que uma pessoa "saiu da linha, bebeu demais, provocou escândalo ou deu vexame" (Fontes Filho, 2006:30).

Para os mais experientes no uso da língua e que tenham conhecimento da origem de uma determinada expressão, será possível saber se ela surgiu em um determinado período histórico ou em determinada situação. Embora seja um exercício bastante lúdico tentar descobrir a origem das EIs, este trabalho não tem como fim específico tratar desse assunto, porque acreditamos que o mais importante é o uso atual das expressões frequentes e também porque há muitas especulações com relação ao estudo da origem das EIs, cujas significações podem não surgir de fontes e informações confiáveis. Qualquer pessoa pode usar o recurso da linguagem denotativa para criar uma origem falsa. A título de curiosidade, ilustramos com a EI citada acima, enfiar o pé na jaca, que, possivelmente, surgiu na época do cangaceiro Lampião, quando Corisco, após ficar 
muito embriagado, literalmente enfiou o pé na jaca, quando voltava ao seu acampamento, e, sem nem ao menos perceber, chegou ao local com a jaca enfiada em seu pé. A partir de então, sempre que alguém ficava embriagado, Lampião dizia para terem cuidado para não pisarem na jaca (Prata, 2003:48).

Portanto, considerando-se o sentido denotativo da expressão enfiar o pé na jaca, diante de uma pessoa com o pé enfiado em uma jaca, ela não será considerada EI. Já com o sentido conotativo, a expressão apresenta uma marca fraseológica forte, sendo vista como uma expressão de alto valor metafórico, de difícil decodificação. A esse respeito, Roncolatto (2001:17) ressalta que “[...] as EIs são frutos de um processo metafórico de criação", desse modo, há um leque de possibilidades previsíveis e imprevisíveis. Para se perceber o sentido denotativo ou conotativo de uma expressão é relevante considerar o contexto de seu uso e a regularidade desse uso. Nesse sentido, podemos dizer que o vocabulário de uma comunidade linguística vai sendo constituído, modificado e enriquecido, principalmente por meio da tradição cultural dessa comunidade. Ensinar EIs nas escolas colabora para resgatar essa tradição, entendendose que muitas expressões podem ser esquecidas e outras podem ser criadas.

O trabalho com EIs em sala de aula, sugerido em nossa pesquisa, é considerado de grande riqueza, pois quando o docente apresenta ao discente as facetas da interpretação conotativa, tais como interpretação de textos, abstração de metáforas e símbolos, ele possibilita acesso aos múltiplos olhares que o sentido denotativo não pode oferecer. Para que essa interpretação seja ainda mais eficiente, faz-se necessário o uso do dicionário especial de EIs, que apresentará possíveis "traduções" da linguagem conotativa da expressão para a linguagem denotativa, tratando-se da língua materna.

\section{O DICIONÁRIO ESPECIAL EM SALA DE AULA}

Por ser uma obra de referência na vida do falante e do estudante, há a grande ambição de que o dicionário supra todas as necessidades de seu público-alvo em seu domínio específico. Muitos estudos no âmbito da Lexicografia Pedagógica vêm sendo realizados para descrever os tipos de dicionários, suas características, finalidades e uso pedagógico.

Essa obra representa a língua e a cultura de um povo, que se renovam em sua atuação linguística e em sua dinâmica histórica. Segundo Biderman (1984:28), “O dicionário é um instrumento cultural que remete tanto à língua como à cultura. $\mathrm{O}$ 
lexicógrafo descreve ambas - língua e cultura - como um todo pancrônico, embora se situe numa perspectiva sincrônica". Tarefa complexa do dicionário é acompanhar essa dinamicidade, reciclando-se e inovando-se de acordo com as correntes ideológicas educacionais e sociais.

Por conta dessa característica, o dicionário é um recurso que contribui muito no enriquecimento e na aprendizagem de uma língua, pois nele estão registradas palavras e expressões que constituem nosso tesouro vocabular, funcionando como uma memória externa, já que só armazenamos uma parcela muito pequena do léxico em nossa memória.

Segundo Krieger (2007:298), entre outros aspectos, o dicionário contribui para ampliação do conhecimento do vocabulário, dos múltiplos significados de palavras e expressões, da norma padrão da Língua Portuguesa, de aspectos históricos, bem como gramaticais dos itens léxicos, de usos e variações sociolinguísticas. A referida autora garante que, por ser um lugar privilegiado de lições sobre a vida (Krieger, 2003), o dicionário pode funcionar como efetivo instrumento didático (Krieger, 2007).

O dicionário geral e o escolar são obras consideradas didáticas ou paradidáticas, habitualmente adotadas nas instituições de ensino, porém, em grande parte das instituições, são pouco utilizados, ou não são explorados criteriosamente como ferramentas de trabalho do docente no ensino de língua. Essa obra lexicográfica tem o posto de informar e oferecer subsídios aos estudantes de língua para melhorar a comunicação.

Por meio desses dicionários, os aprendizes podem ter conhecimento de como a norma culta é registrada, para que possam e saibam utilizá-la na recepção e na produção textual. Biderman (1984) considera o dicionário um instrumento de orientação a quem o consulta e afirma que os significados e usos das palavras, dispostos na obra lexicográfica, auxiliam na expressão de ideias e sentimentos de seu usuário. Concordamos com a memorável estudiosa por acreditar que, na medida em que o estudante de uma língua utiliza o dicionário, ele se torna mais autônomo e preciso em suas colocações e construções linguísticas, tornando-se, consequentemente, sujeito ativo e reflexivo na sociedade e no ambiente escolar.

Além de todas essas características do dicionário, a questão cultural também deve ser ressaltada. Em Dubois et al. (1973), a obra lexicográfica é descrita como um objeto cultural, fornecedor de informações que permitem a tradução de uma língua para 
outra, no caso de dicionários bilíngues. $\mathrm{O}$ autor salienta que o dicionário, além de aumentar o "saber cultural" do estudante, oferece domínio de seus meios de expressão.

Como o dicionário escolar é uma obra voltada especialmente a estudantes e aprendizes de língua, é extremamente necessário que o discernimento crítico e o rigor linguístico sejam garantidos a seus usuários. Nesse caso, o dicionário pode ser visto como um tipo especial de obra didática e é de extrema importância que ofereça um universo linguístico abrangente aos consulentes, de acordo com a realidade em que estes estejam inseridos.

O dicionário deve ser um instrumento de ensino que oriente os estudos em sala de aula, mas essa orientação deve partir das noções que o educador possui acerca dos níveis linguísticos dos alunos e do conhecimento das obras lexicográficas e a quem se destinam. Desse modo pode auxiliar na escolha da obra mais conveniente para o grupo de estudantes e o nível de ensino.

Além de conhecer o dicionário, Höfling et al. (2004) garantem que é função do professor diferenciar as atividades baseadas no uso desse material quanto ao nível linguístico dos aprendizes, quanto ao contexto educacional e quanto ao número de aprendizes.

Entendemos que o educador deve estar preparado para lidar com novas técnicas de ensino, considerar os diversos contextos do aluno e do sistema escolar no qual está inserido. Ele deve, ainda, conhecer as distintas obras lexicográficas existentes no mercado que sejam adequadas aos níveis de cada usuário e saber aplicar atividades direcionadas que o auxiliem, como um diagnóstico, para que conheça os níveis desses alunos.

O que se observa, porém, é um desinteresse e mesmo falta de informação do professor em relação ao uso sistemático dos dicionários gerais. Essa falta de informação se acentua ainda mais quando se trata do conhecimento e uso de dicionários especiais.

Em pesquisa anterior, Rodrigues (2010:72) constatou que, embora os professores afirmem conhecer os dicionários especiais, entre eles "há certa confusão entre o que sejam dicionários especiais e de especialidade", pois, quando interrogados sobre os títulos de obras especiais que possuíam, fizeram confusão. Rodrigues (2010) faz assim a distinção:

Dicionários especiais são obras lexicográficas que apresentam especificidades da língua, descrevendo algumas características que o dicionário padrão não consegue contemplar de forma aprofundada. É o caso dos dicionários de expressões 
idiomáticas, que apresentam expressões próprias da língua, mas que não são tratadas de modo sistemático no dicionário padrão, por fazerem parte de um léxico especial e não possuírem o mesmo sentido se suas unidades forem analisadas separadamente. Os dicionários de especialidade, por sua vez, apresentam termos técnicos de determinada área, com o léxico próprio para profissionais que o utilizam, como os dicionários jurídicos, por exemplo, utilizados, muitas vezes, por especialistas da área. Assim, dentre as respostas dos professores, acertaram apenas aqueles que mencionaram os dicionários de verbos e regimes e o de expressões. (Rodrigues, 2010:72-73)

Nessa investigação, foram aplicados questionários destinados a alunos e professores de duas escolas (uma da rede particular de ensino e outra da rede estadual de ensino). Para complementar os dados, também foi observado o comportamento dos usuários dos dicionários nas bibliotecas e sala de aulas das referidas instituições, por meio da aplicação de atividades preparadas sobre as EIs.

\section{A visão dos professores}

O questionário direcionado a oito professores de Língua Portuguesa das redes estadual e particular de ensino teve o intuito de verificar se no Ensino Fundamental (do $6^{\circ}$ ao $9^{\circ}$ ano) havia o uso sistemático de dicionários gerais e se existia a informação a respeito de dicionários de EIs. Também se questionou se era praticada a consulta em sala de aula e se eram trabalhados textos e atividades com EIs nas aulas de Língua Portuguesa.

Entre as respostas mais relevantes dos professores, referimos que tanto aqueles das escolas particulares quanto os das estaduais possuem e utilizam um ou mais dicionários, citando os mais comuns, o Aurélio e o Houaiss. Contudo, os resultados apontaram que na escola estadual os docentes tinham mais liberdade ou iniciativa para $o$ uso do dicionário em sala de aula que na particular e também que trabalhavam mais textos em que as EIs apareciam. Quando o uso do dicionário se dava, frequentemente era em consulta individual dos alunos.

Outro dado obtido por meio de uma das questões é o fato de os professores reconhecerem o uso recorrente dessas expressões tanto no discurso oral quanto nos textos dos alunos e afirmarem unanimemente que, no ato da correção dos textos escritos, costumam fornecer uma "explicação do sentido da EI e discussão sobre sua riqueza expressiva”, conforme alternativa fornecida por Rodrigues (2010:75). Mesmo sem ter averiguado a veracidade dessa resposta, já que para isso seria preciso fazer uso de outros recursos, a resposta foi surpreendente, porque acreditávamos que essas 
expressões, assim como as gírias, seriam simplesmente riscadas dos textos, banidas do registro culto, por professores tanto das escolas públicas quanto das privadas. Isso seria natural, dado que o ensino de língua materna privilegia a norma culta e a escrita. Sobre essa questão, Rodrigues manifesta a seguinte opinião:

O que deve ser de compreensão do aluno é que, se o texto não admitir o uso de EIs, elas devem ser evitadas ou substituídas por unidades adequadas ao estilo ou gênero textual proposto. As EIs não podem ser relegadas ao esquecimento por serem mais frequentes na oralidade. Seu aparecimento em um texto deve servir de mote para uma discussão. Dessa maneira, o docente poderá mostrar que as EIs representam unidades dinâmicas e ricas da língua, especialmente por muitas refletirem a história e a cultura dos usuários da Língua Portuguesa. (Rodrigues, 2010:76).

Os resultados gerais do questionário demonstraram que na escola particular percebeu-se uma preocupação exacerbada com o cumprimento da programação curricular, o que impedia, muitas vezes, o uso sistemático de dicionários em sala de aula e a aplicação de atividades que tratassem do léxico especial. Os fraseologismos eram apenas referidos como fenômenos da língua quando apareciam em alguns textos do livro didático. Esse problema afetou até mesmo o trabalho da pesquisadora na aplicação de atividades com EIs. A escola pública, por sua vez, mostrou-se mais aberta a esses tópicos.

\section{A visão dos alunos}

O questionário aplicado aos alunos (104 alunos da escola estadual e 119 da escola particular - totalizando 223, todos das turmas "A" do período matutino), permitiu, ao se comparar com as respostas dos professores, perceber se eles conheciam os dicionários especiais, se o trabalho com as EIs era realizado de fato nas aulas de Língua Portuguesa e como o professor lidava com os textos que apresentam EIs e outras unidades fraseológicas, quando elaborados pelos discentes.

A mesma pesquisa obteve um dado interessante que mostra bem a diferença entre os alunos da escola pública e os da particular: praticamente $70 \%$ dos alunos da rede pública não possuíam um dicionário escolar, enquanto $100 \%$ dos alunos da rede privada possuíam. Quanto ao uso que fazem dessa obra, a maior parte deles (197 dos 223) costuma pesquisar o significado das palavras desconhecidas, alguns (23) procuram informações sobre a ortografia e poucos (três) para conhecer novas palavras e para resolver dúvidas gramaticais. 
Uma das perguntas mais importantes visava diagnosticar como os alunos entendiam as EIs. Os dados mostraram que, dos 104 alunos da escola estadual, 35 informaram que não sabiam o que são EIs, um número considerável, levando em conta que o grupo engloba alunos do $6^{\circ}$ ao $9^{\circ}$ ano. Na escola particular, o número é bem próximo, 38 alunos dos 119 também não as conhecem. Curiosamente, desses 38, 35 pertenciam a uma única turma do $8^{\circ}$ ano. Provavelmente isso ocorreu porque essa turma não teve acesso a nenhum texto contendo EIs.

Essa questão não tinha como objetivo saber se os alunos eram capazes de utilizar uma EI, mas sim se tinham noção da existência dessa nomenclatura, porque mesmo aqueles que disseram desconhecer as utilizam. Isso foi comprovado na pergunta seguinte, quando foi solicitado aos alunos que indicassem, entre doze opções, quais seriam as EIs, que estavam misturadas com outros tipos de fraseologismos, como provérbios e gírias. A maioria dos alunos assinalou as frases corretas. Em complementação, foi questionado se algumas dessas expressões já haviam sido trabalhadas em sala de aula. 43 alunos da rede estadual afirmaram que já haviam sido trabalhadas frases com EIs em sala de aula, enquanto 61 disseram que não; dos alunos da rede privada, 55 confirmaram o trabalho com frases e EIs contra 64 que garantiram que não. Então foi solicitada uma justificativa para a resposta, explicando como a atividade havia sido desenvolvida, e os alunos relataram o seguinte:

"Não me lembro", "Em textos", "Com explicações", "Nos textos em que elas apareciam", "No livro de Português do ano passado", "Lendo livros e redações", "Em um quadro que havia no livro do ano passado", "Nas apostilas da antiga escola", "Em conversas com os colegas".

(Rodrigues, 2010:82)

Sobre a questão do uso das EIs nas produções textuais, questionou-se aos alunos se os professores solicitavam a substituição destas sempre que apareciam em seus textos. Considerando os 223 alunos consultados, 101 afirmaram que sim, enquanto 122 asseguram que os professores não pediam para que as EIs fossem substituídas. Essa resposta diverge um pouco da afirmação dos professores que disseram que não "riscam" as EIs dos textos dos alunos. Nas justificativas dos alunos sobre como isso era realizado, afirmaram que as EIs deveriam ser trocadas por frases que fizessem sentido no texto ou que os professores pediam para que consultassem o dicionário e substituíssem a expressão "por seu verdadeiro sentido". Como exemplo, um aluno colocou: 
"Acordei com o pé esquerdo" = Acordei mal-humorado

É interessante que isso tenha sido colocado, porque denota um indício de que às vezes o trabalho com EIs é mesmo realizado em sala de aula. Contudo, falta desenvolver esse quadro, usando os dicionários mais adequados, os dicionários especiais de Expressões Idiomáticas, em vez dos dicionários gerais e escolares e implementar atividades mais sistemáticas para ampliar a riqueza vocabular dos alunos de Língua Portuguesa.

\section{CONSIDERAÇÕES FINAIS}

O dicionário geral escolar apresenta apenas uma pequena parcela de EIs e outros fraseologismos, como é o caso de pôr a boca no mundo, que significa "Dar gritos; gritar, bradar" (Ferreira, 2004), incluída nos exemplos da entrada boca, portanto, não incluída em ordem alfabética no dicionário.

Esse tipo de dicionário geral não é capaz de tratar adequadamente nem mesmo das EIs mais comuns da língua, o que caberia, sem dúvida, a um dicionário especial, que pode conter um número muito maior de EIs, organizadas tanto semasiologicamente quanto onomasiologicamente, e que pode ser apresentado aos alunos mesmo antes do ensino fundamental. É um dicionário que não funciona apenas para uma consulta eventual, pode ser lido, porque geralmente seus verbetes são bastante divertidos.

Confirmamos, portanto, com base na coleta de dados e na análise dos resultados obtidos nas duas escolas, a não utilização de dicionários de expressões idiomáticas nas aulas de Língua Portuguesa, inclusive as bibliotecas das escolas envolvidas não contam com nenhum tipo de dicionário especial. Além disso, muitos professores de Língua Portuguesa não conhecem esse tipo de obra e negligenciam sua importância na construção intelectual dos alunos.

Todas essas questões trouxeram um diagnóstico localizado, mas são importantes para serem colocadas em todos os contextos escolares. Dependendo das respostas, devese promover maior quantidade de cursos de formação para atualização dos professores e prover as bibliotecas de dicionários mais variados.

Embora pareça um tanto ingênua a ideia de que os dicionários especiais sejam sistematicamente adotados nas escolas, quando estas já estão sobrecarregadas de grande quantidade de conteúdos (geralmente cumpridos sem qualidade), os estudos em 
Lexicografia Pedagógica visam colaborar para a divulgação de aspectos teóricos, que só vêm a contribuir para o exercício do trabalho docente, trazendo novos recursos e mais aprimoramento para a qualidade do ensino. Uma vez que as EIs são exemplos da dinamicidade da língua, é de suma importância que os aprendizes saibam disso. Em razão disso, como ilustração, colocamos em anexo (Anexo 1) algumas atividades que foram utilizadas em nossa pesquisa.

\section{REFERÊNCIAS}

Biderman, M. T. C. (1984). O dicionário padrão da língua. Alfa: Revista de Linguística, Araraquara, v. 28, 27-43, Suplemento. (2001). Teoria linguística. São Paulo: Martins Fontes.

Carrascoza, J. A. (2007). Qual é a graça? In: Sistema Maxi de Ensino. Londrina: Maxiprint Editora, 31-32.

Dubois, J. et al. (1973). Dicionário de linguística. São Paulo: Cultrix.

Fontes Filho, A. (2006). O dito pelo não dito: dicionário de expressões idiomáticas. São Paulo: Libra Três.

Höfling, C.; Tosqui, P.; Parreira, M. C. (2004). O dicionário como material didático na aula de língua estrangeira. São Paulo: LAEL/PUC-SP. v.13. CD-ROM.

Krieger, M. G. (2003). Dicionário de língua: um instrumento didático pouco explorado. In: Toldo, C. S. (Org.). Questões de linguística. Passo Fundo: Universidade de Passo Fundo, 70-87.

(2007). O dicionário de língua como potencial instrumento didático. In: Isquerdo, A. N.; Alves, I. M. (Org.). As ciências do léxico. Campo Grande: Ed. UFMS; São Paulo: Humanitas, v. 3, 295-309.

Ferreira, A. B. H. (2004). Novo dicionário Aurélio da língua portuguesa. 3. ed. rev. atual. Curitiba: Positivo.

Ortíz Alvarez, M. L. (2000). Expressões idiomáticas do português do Brasil e do espanhol de Cuba: estudo contrastivo e implicações para o ensino do português como língua estrangeira. Tese de Doutorado, Instituto de Estudos da Linguagem, Universidade Estadual de Campinas, Campinas.

Prata, M. (2003). Mas será o Benedito? São Paulo: Globo.

Riva, H. C. (2008). Dicionário onomasiológico de expressões idiomáticas da língua portuguesa do Brasil. São José do Rio Preto, Tese de Doutorado, UNESP. 
Rodrigues, G. (2010). Estudo sobre as expressões idiomáticas e o uso de dicionários especiais da língua portuguesa no ensino fundamental. São José do Rio Preto, Dissertação de Mestrado, UNESP.

Roncolatto, E. (2001). Expressões idiomáticas do português do Brasil e do espanhol da Colômbia: análise, classificação e equivalências. Tese de Doutorado, Faculdade de Ciências e Letras, Universidade Estadual Paulista, Assis.

Tagnin, S. (1989). Expressões idiomáticas convencionais. São Paulo: Ática.

Welker, H. A. (2004). Dicionários: uma pequena introdução à Lexicografia. Brasília, DF: Thesaurus.

(2006). O uso de dicionários: panorama geral das pesquisas empíricas. Brasília, DF: Thesaurus.

(2008). Panorama geral da lexicografia pedagógica. Brasília, DF: Thesaurus.

Xatara, C. M. (1998). A tradução para o português de expressões idiomáticas em francês. Tese de Doutorado, Faculdade de Ciências e Letras, Universidade Estadual Paulista, Araraquara.

\section{AS AUTORAS}

Gislaine Rodrigues Matias é graduada em Licenciatura em Pedagogia pela Faculdade Dom Bosco (FAECA - 2002) e em Letras pela Faculdade Uniceres (2007), com título de mestre (2010) em Estudos Linguísticos pela Universidade Estadual Paulista Júlio de Mesquita Filho (UNESP-IBILCE, 2010), com bolsa Fapesp sob processo $\mathrm{n}^{\mathbf{0}}$ 2008/03336-1. Está cursando o doutorado em Estudos Linguísticos na UNESP-SJRP e é membro do GAMPLE - Grupo Acadêmico Multidisciplinar: Pesquisa Linguística e ensino.

E-mail: girodrigues164@yahoo.com.br

Maria Cristina Parreira da Silva é graduada em Licenciatura em Letras pela Universidade Estadual Paulista Júlio de Mesquita Filho (UNESP-IBILCE, 1992), com título de mestre (1998) e de doutora (2002) em Linguística e Língua Portuguesa pela UNESP-FLCar. É professora de Língua Francesa na graduação da UNESP de São José do Rio Preto desde 2003 e na pós-graduação desde 2007, na linha de pesquisa Descrição e análise do Léxico Geral. Participa de dois grupos de pesquisa registrados no CNPq (Lexicologia e Lexicografia contrastiva e A fraseologia e sua equação nas subáreas da Linguística Aplicada) e é líder do GAMPLE - Grupo Acadêmico Multidisciplinar: Pesquisa Linguística e ensino.

E-mail: cristinaparreira@ sjrp.unesp.br 
ANEXO 1

ATIVIDADES VOLTADAS AO TRABALHO COM EXPRESSÕES IDIOMÁTICAS

- Leia o texto com muita atenção e depois faça as atividades propostas.
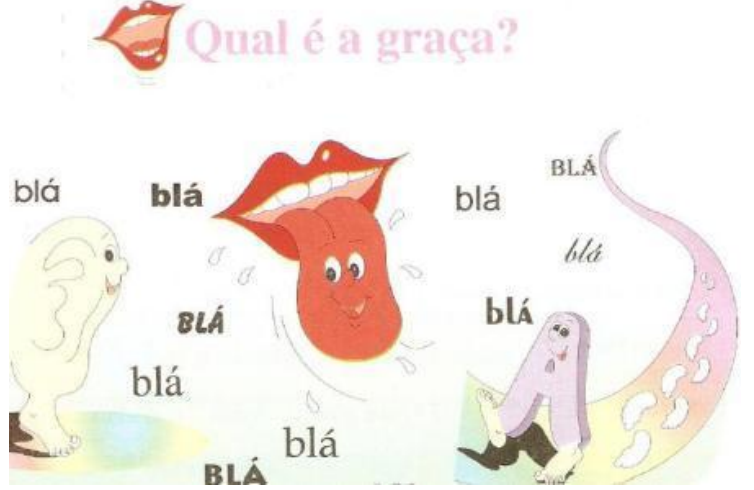

Engraçada a nossa língua. Ela tem cada coisa que a gente não entende se levar muito a sério. Por exemplo, o pé do ouvido. Não é um ouvido que tem pé, põe sapato e sai por aí correndo atrás de conversa fiada. Não é um pé que joga bola, faz gol e tem bolha às vezes. É outra coisa muito diferente, não custa explicar se é que dá para entender. O mais legal está em deixar cada um descobrir por si mesmo. Bem, quem não sabe o que significa pode procurar no dicionário, que desta vez eu não vou ajudar. Só vou falar mais um pouco sobre o assunto. O ouvido tem a parte de cima e a de baixo. É igual ao corpo da gente: a parte que fica lá embaixo recebe o nome de pé. Daí o pé do ouvido. Quer dizer, a gente não pode levar tudo ao pé da letra. Epa! Olha aí outro pé. Só que agora eu deixo para você descobrir qual a graça dele. Ah, mais uma palavrinha! Quando disse lá em cima que a língua é engraçada, estava falando daquela que a gente fala, a portuguesa. Não vá levar tudo a sério e confundir com a outra, a língua que a gente morde quando está com muita fome.

João Anzanello Carrascoza In: Sistema Maxi de Ensino (2007)

1- Relacione a segunda coluna de acordo com a primeira:
(a) A língua portuguesa
( ) faz gol, usa sapato e tem bolha.
(b) O pé do ouvido
( ) a gente morde quando está com fome.
(c) O pé que joga bola
( ) é pensar exatamente aquilo que se ouviu.
(d) A língua que está na boca
( ) é aquela que a gente fala.
(e) Ao pé da letra
( ) é um tapa com muita força no ouvido.

2- Você consegue explicar o que significam estas expressões? barriga da perna -

maçãs do rosto -

peito do pé -

boca do estômago -

3- Numere as figuras de acordo com as expressões dadas:
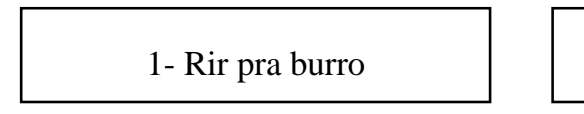

2- Quebrar o galho

4- Dar nome aos bois
5- Falar pelos cotovelos
3- Pôr a boca no mundo

6- Puxar o saco 


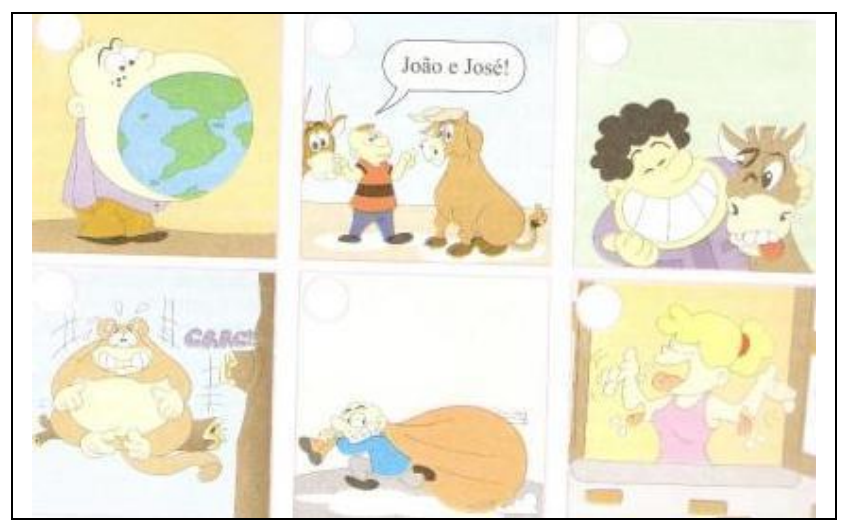

Agora, faça dois desenhos que representem duas expressões idiomáticas conhecidas ou utilizadas por você.

Agora, responda ao entrevistador:

4- Você acha que um dicionário geral o auxiliaria a entender os sentidos das expressões desconhecidas por você? Por quê?

5- Você acha que é interessante o uso de dicionários de expressões idiomáticas da língua em atividades como essas? Por quê? 